\title{
¿FRUTO DE LA PARRA ENVENENADA? ALGUNAS OBSERVACIONES COMPARADAS SOBRE LA CONSTITUCIÓN CHILENA*
}

\author{
Tom Ginsburg \\ University of Chicago Law School
}

\begin{abstract}
Resumen: ¿Puede una constitución nacida en dictadura servir a la democracia, o está inevitablemente marcada por las circunstancias de su nacimiento? Ésta es una pregunta muy importante para la política chilena actual, pero en esto Chile no está solo. Cerca del $20 \%$ de las constituciones vigentes actualmente fueron redactadas durante períodos no democráticos. La constitución de Chile, sin embargo, forma parte de un grupo más pequeño que denominaremos constituciones
\end{abstract}

Tom Ginsburg. PhD en la Universidad de California en Berkeley. Profesor de derecho en la Universidad de Chicago. Reconocido experto en las realidades constitucionales de distintos países, sus debates, continuidades y cambios. Sus libros incluyen Judicial Review in New Democracies (2003); Rule by Law: The Politics of Courts in Authoritarian Regimes (2008) y The Endurance of National Constitutions (2009).

* Agradezco a Javier Couso, David Landau, James Melton y Pasquino Pasquale por sus útiles comentarios y discusiones, y a Lucas Sierra por la generosa invitación a pensar sobre Chile. Estoy en deuda además con Natalia Ginsburg, Suzanne Hillal y David King por asistencia en la investigación. Estoy agradecido también de mis colegas y co-autores Zachary Elkins y James Melton por el permiso concedido para usar figuras de nuestro trabajo conjunto. La traducción desde el inglés fue realizada por Javier Gallego Saade (CEP). 
autoritarias transformadoras. Estas constituciones (1) han sido redactadas para ayudar de modo explícito al retorno a la democracia electoral luego de un período de tiempo; (2) reflejan ciertos objetivos políticos pensados para ser permanentes; y (3) contienen un mecanismo de reforzamiento para asegurar que ambos objetivos se logren. Este trabajo analiza luego cómo la reforma constitucional puede alcanzarse, sobre la base de evidencia comparada.

Palabras clave: constitución, democracia, tribunal constitucional, reforma constitucional, constitucionalismo autoritario, asamblea constituyente, derecho comparado, leyes orgánicas constitucionales.

Recibido: enero 2014; aceptado: enero 2014.

FRUIT OF THE POISONED VINE? SOME COMPARATIVE OBSERVATIONS ON CHILE'S CONSTITUTION

Abstract: Can a constitution born in dictatorship serve democracy, or is it inevitably tainted by the circumstances of its birth? This question is central in Chilean politics today, but Chile is not alone. Roughly 20\% of constitutions in force today were drafted during undemocratic periods. Chile's constitution, however, is part of a smaller set which we call transformational authoritarian constitutions. These constitutions (1) are explicitly framed as helping to structure a return to electoral democracy after a period of time; (2) reflects certain policy goals designed to be permanent; and (3) contain an enforcement mechanism to ensure that both these goals are met. The article then goes on to consider how constitutional reform should be achieved, drawing on comparative evidence.

Keywords: constitution, democracy, constitutional court, constitutional reform, authoritarian constitutionalism, constituent assembly, comparative law, constitutional organic laws.

Received: January 2014; accepted: January 2014.

${ }_{i} \mathrm{P}$ uede una constitución nacida en dictadura servir a la democracia o está inevitablemente marcada por las circunstancias de su nacimiento? Esta es una pregunta muy importante para la política chilena actual. También es una pregunta importante para ser considerada por abogados de derecho constitucional comparado. La constitución chilena 
de 1980 representa una importante pero poco estudiada categoría de constituciones: aquellas redactadas durante una dictadura que sobreviven la transición a la democracia. Otros ejemplos prominentes incluyen la constitución de México adoptada en 1917, la de Indonesia de 1945, la de Turquía de 1982, la de Portugal de 1974, y la de Taiwán, redactada en territorio de China en 1947. Ejemplos menos conocidos incluyen la constitución redactada por las fuerzas militares de Panamá en 1972 y la de Guyana de $1980^{1}$. Aprovecharé esta oportunidad para especular en torno a esta categoría y ofrecer algunas ideas tentativas sobre la pregunta de si - y si así es cómo - ha de reemplazarse el documento. Estas observaciones, por cierto, deben tomarse por lo que son: ideas de un extranjero desinformado que no ha examinado el debate chileno en profundidad. No obstante, espero que parte de los datos que aportaré contribuyan a la discusión en este país.

¿Por qué líderes en democracia habrían de retener una constitución de dictadores? Como cuestión inicial, uno podría pensar en esta categoría de países como ejemplos de casos en que cambios formales de constituciones no tienen correlación con auténticos cambios constitucionales. En algunos países, los procesos de transición entre democracia y dictadura tienden a estar marcados por revisiones y reemplazos constitucionales formales. En otros, ambos fenómenos están menos vinculados. Mis colegas y yo disponemos de esta observación a la hora de argumentar que el cambio constitucional es un fenómeno distinto del cambio de régimen ${ }^{2}$. Chile (figura $n^{\circ} 1$ ) es un ejemplo de manual ${ }^{3}$. Se trata de un país cuya historia está marcada por una estabilidad constitucional a la par de fluctuaciones políticas. De esta forma, la Constitución de 1980 tiene algo en común con sus predecesoras de 1833 y 1925: ha regido durante un largo período de grandes cambios políticos. Por cierto, la Constitución de 1833 es la decimoquinta más duradera entre más de 900 constituciones nacionales adoptadas desde 1789. De una manera no muy distinta, la Constitución de 1980 es hoy más vieja que la mitad de las constituciones hoy vigentes en el mundo.

${ }^{1}$ La tabla $n^{\circ} 1$ contiene un listado que incluye algunos casos ambiguos, como la constitución de Fujimori de 1993, y aquellas redactadas durante transiciones. La de Argentina, de 1853, encaja en la categoría, sin perjuicio de ciertas reformas importantes de 1994.

2 Elkins et al. (2009).

${ }^{3}$ Agradezco a mi colega James Melton por esta figura. 


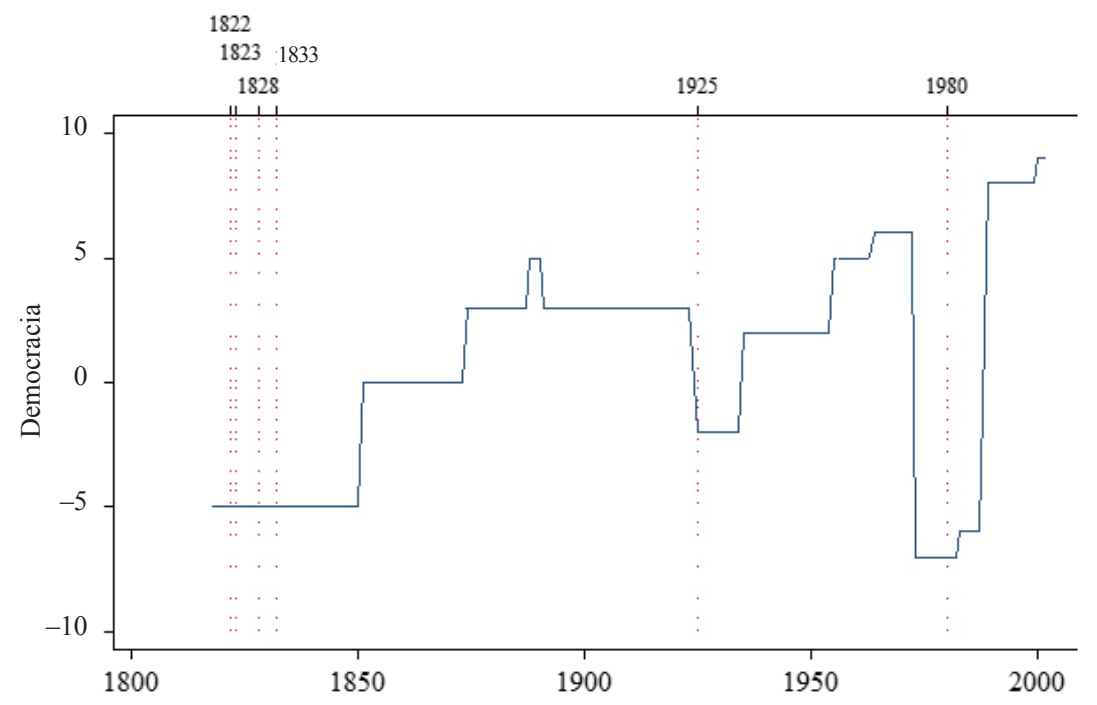

Hay otras posibles razones para que un país retenga una constitución vieja. Una es que la constitución vieja se deba mantener por razones políticas: ya sea porque goza de cierta legitimidad ante parte de la población general o bien porque los proponentes originales retienen todavía poder suficiente para bloquear cualquier intento de reemplazo. Los casos de México e Indonesia pueden considerarse ejemplos de la primera dinámica. En ambos casos la constitución se asociaba a un evento significativo - una revolución o momento de independencia- y entonces conservaba su legitimidad sin importar su uso por funcionarios autoritarios. Chile, por otro lado, representa un caso de poder de veto ejercido contra cambios significativos. Las fuerzas políticas vinculadas al otrora régimen militar juegan un potencial rol constrictivo, y siguen beneficiándose de un cuerpo de instituciones - el sistema electoral binominal, requerimientos de quórums supramayoritarios en torno a ciertas reglas y la revisión ex ante por un tribunal constitucional- que todavía mantienen su importancia en la actualidad.

Este trabajo busca contribuir a algunos significativos debates de derecho constitucional comparado. En particular, se ha puesto mayor atención en el rol de las constituciones en regímenes autoritarios. Es común observar que las constituciones de las dictaduras se des- 
criben como meras farsas o manifestaciones de "constituciones sin constitucionalismo"4. Siguiendo esta línea de pensamiento, podríamos pensar que las constituciones consisten en instituciones inherentemente democráticas y que entonces las constituciones autoritarias son un epifenómeno. Pero contribuciones recientes han revelado que, en contraste con la visión simplista de las constituciones autoritarias como meros fraudes, éstas cuentan con una variedad de funciones sofisticadas que sirven a los regímenes para el cumplimiento de ciertos objetivos, como por ejemplo el compromiso con derechos de propiedad, coordinación de la élite dirigente o comunicaciones a los sujetos de la constitución relativas a las políticas y metas del régimen ${ }^{5}$. Estas funciones pueden de hecho extender el régimen autoritario ${ }^{6}$. Estas constituciones tienen también en ciertos casos propiedades latentes, que pueden servir para perjudicar el régimen autoritario o bien emerger como herramientas de coordinación cuando se encuentra cerca del derrumbe. Una comprensión de la lógica de la constitución de Pinochet contribuye a enriquecer esta literatura.

El presente trabajo se organiza como sigue. Primero consideramos la categoría general de constituciones autoritarias transformadoras, aquellas diseñadas en dictaduras para guiar y constreñir un eventual retorno a la democracia. Chile sirve aquí quizás como un ejemplo paradigmático de esta categoría, pero no es el único. Luego demostramos que en la forma, estas constituciones son bastante similares a aquellas que encontramos en democracias, con el aditivo de provisiones especiales de veto por las minorías. A continuación consideramos la cuestión relativa a la enmienda o reemplazo de estas constituciones, y en el caso de lo segundo, si debe obtenerse el reemplazo por medio de una asamblea constituyente, por medio de la legislatura o por otra modalidad. Finalmente, se discute alguna evidencia relativa al rol de las cortes y de la ciudadanía en la reforma constitucional.

\section{Constituciones autoritarias transformadoras como categoría}

¿Qué es una constitución autoritaria? Como lo argumentamos en otra parte con Zach Elkins y James Melton, la pregunta es más difícil de

\footnotetext{
${ }^{4}$ Law \& Versteeg (2013); Okoth-Okendo (1993: 65-85).

${ }^{5}$ Ginsburg \& Simpser (2013).

${ }^{6}$ Albertus \& Menaldo (2013).
} 
lo que parece ${ }^{7}$. Se podría pensar que una constitución es autoritaria si gobierna un régimen autoritario, y democrática si gobierna un régimen democrático. En este sentido, el tipo de constitución es congruente con el tipo de régimen. Pero esto dejaría fuera de la definición la categoría que Chile representa. Sabemos que las decisiones constitucionales tienen extensos legados, y modificarlas resulta costoso. También sabemos que regímenes democráticos y autoritarios pueden presentarse de modo secuencial aun bajo la misma constitución. De este modo, podemos perder de vista una importante subcategoría de casos de herencias autoritarias si identificamos simplemente el cambio constitucional con el cambio del sistema político. El cambio constitucional, como sostenemos aquí, es distinto del cambio de régimen político, aunque en muchos casos ambos puedan estar íntimamente ligados ${ }^{8}$.

¿Es una constitución "autoritaria" si inició su vida bajo una situación autoritaria pero evolucionó hasta reflejar en último término muchas de las promesas democráticas formales del documento? Tenemos que considerar la cuestión de si aquellas constituciones que son diseñadas para evolucionar pueden integrar su propia subcategoría. Esta aproximación adoptaremos aquí. Llamaremos constitución "transformadora" a aquella diseñada para facilitar un cambio de régimen, aunque sea gradual.

Siguiendo a Elkins et al. comenzamos caracterizando una constitución como autoritaria simplemente si es redactada en un año en que el país en cuestión califica como autoritario, y democrática si se redacta en un año que califica como democrático ${ }^{9}$. Usamos una codificación binaria, siguiendo gran parte de la literatura de política comparada ${ }^{10}$. Usando estos criterios y apoyándonos en la base de datos del Comparative Constitutions Project relativa a constituciones de Estados independientes desde 1789, observamos que la gran mayoría de estos documentos fueron redactados en regímenes autoritarios. Como lo muestra la figura $\mathrm{n}^{\circ} 2$ (tomada de Elkins et al. 2013), 695 de 846 sistemas constitucionales históricos sobre los cuales tenemos datos re-

${ }^{7}$ Elkins et al. $(2013)$.
${ }^{8}$ Elkins et al. $(2009)$.
${ }^{9}$ Elkins et al. $(2013)$.
${ }^{10}$ La caracterización se basa en el sistema de medición del proyecto Unified Democracy Scores. Véase Pemstein et al. (2010). Elkins et al. (2013) describe la medición. 
FIGURA N ${ }^{\circ}$ 2: $\quad$ NÚMERO DE CONSTITUCIONES SEGÚN EL RÉGIMEN EN QUE NACIERON

Universo: 907 constituciones promulgadas en Estados independientes entre 1800 y 2008

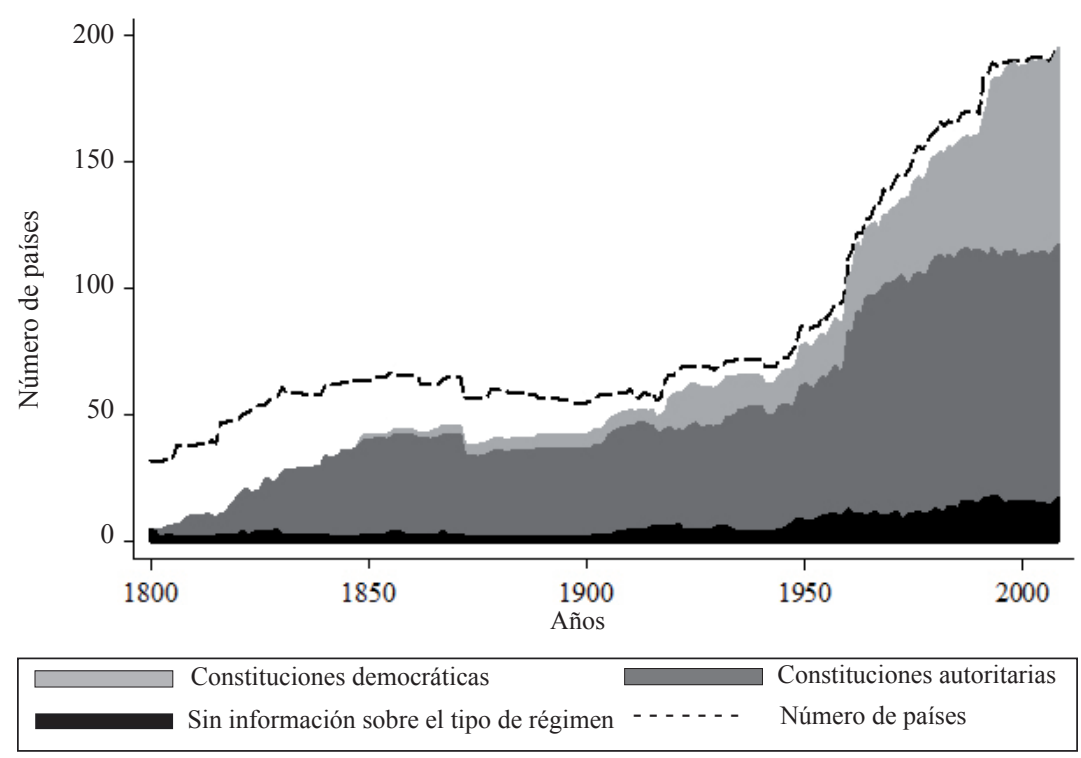

lativos al tipo de régimen serían considerados autoritarios ${ }^{11}$. $\mathrm{Y}$ a pesar de que vivimos actualmente en una "era de democracia", algo así como el $56 \%$ de las constituciones actualmente vigentes fueron redactadas por dictadores ${ }^{12}$.

Usando estos criterios, podríamos creer que el número de documentos autoritarios transicionales es de hecho elevado. La tabla $n^{\circ} 1$ muestra las constituciones actualmente vigentes en democracias que fueron redactadas por líderes autoritarios. En ciertos casos, los redactores fueron monarcas o revolucionarios. Pocos casos parecen reflejar el modelo chileno en el que un régimen militar buscó implementar un conjunto de límites que habrían de guiar y constreñir el retorno a la política electoral, aunque el de Turquía de 1982 representa un caso análogo importante sobre el que volveremos más adelante.

${ }^{11}$ El universo de sistemas constitucionales entre 1789 y 2008 suma 911; contamos con datos sobre tipo de régimen de 846 de éstos.

12 Elkins et al (2013:145-146). 
TABLA N ${ }^{\circ}$ 1: CONSTITUCIONES HOY VIGENTES EN DEMOCRACIA REDACTADAS EN DICTADURA

\begin{tabular}{ll}
\hline Argentina 1853 & México 1917 \\
Bélgica 1831 & Micronesia 1981 \\
Benín 1990 & Nepal 2006 \\
Burundi 2004 & Nicaragua 1987 \\
Cabo Verde 1980 & Noruega 1814 \\
Chile 1980 & Países Bajos 1815 \\
El Salvador 1983 & Panamá 1972 \\
Georgia 1995 & Paquistán 2002 \\
Ghana 1992 & Perú 1993 \\
Guyana 1980 & Samoa 1962 \\
Hungría 1949 & Santo Tomé y Príncipe 1975 \\
India 1949 & Seychelles 1993 \\
Indonesia 1959 & Tailandia 2007 \\
Japón 1946 & Taiwan 1947 \\
Liberia 1986 & Turquía 1982 \\
\hline
\end{tabular}

La figura $n^{\circ} 3$ (también extraída de Elkins et al. 2013) muestra de alguna manera el sentido de la distribución de constituciones sobre la base de estos criterios a lo largo del tiempo. El área amplia de color gris oscuro muestra el grupo de documentos autoritarios que perduraron como autoritarios, y que de alguna forma pueden considerarse como parte de un tipo puro. Si los países regidos por estos documentos giraban hacia una democracia, ello se vería acompañado de un cambio constitucional. El área más reducida de color gris claro debajo de los casos "puros" de constituciones autoritarias representa aquellas constituciones que fueron escritas por líderes autoritarios pero que sobrevivieron una transición a la democracia en algún momento de su existencia. Aun cuando este grupo más pequeño integra sólo el 10\% de las constituciones históricas, cerca del $20 \%$ de las constituciones vigentes hoy son de esta variedad (véase la lista en la tabla $n^{\circ} 1$ ). Por cierto, esta lista incluye casos — tales como Burundi, Ghana o Japón- que se encontraban en proceso de democratización cuando la constitución 
se redactó. Sin perjuicio de ello, ésta es una categoría que amerita una mayor investigación.

Asumiendo que este grupo conforma una categoría coherente, ¿cuáles son los criterios que distinguen a una constitución autoritaria transformadora? Como tipo ideal, propongo los siguientes a manera de criterios esenciales: (1) la constitución debe explícitamente estar orientada a permitir un retorno a una democracia electoral, luego de un período que puede o no estar especificado; (2) la constitución debe reflejar ciertos objetivos políticos diseñados para ser permanentes, esto es, para constreñir al futuro régimen democrático; y (3) la constitución debe proveer un mecanismo de reforzamiento que permita asegurar que los dos objetivos anteriores se realicen. En otras palabras, la constitución

\section{FIGURA N ${ }^{\circ}$ 3: NÚMERO DE CONSTITUCIONES DE ACUERDO AL RÉGIMEN EN QUE NACIERON, ORDENADAS SEGÚN EXPERIMENTARON O NO UN CAMBIO DE RÉGIMEN}

Universo: 907 constituciones promulgadas en Estados independientes entre 1800 y 2008

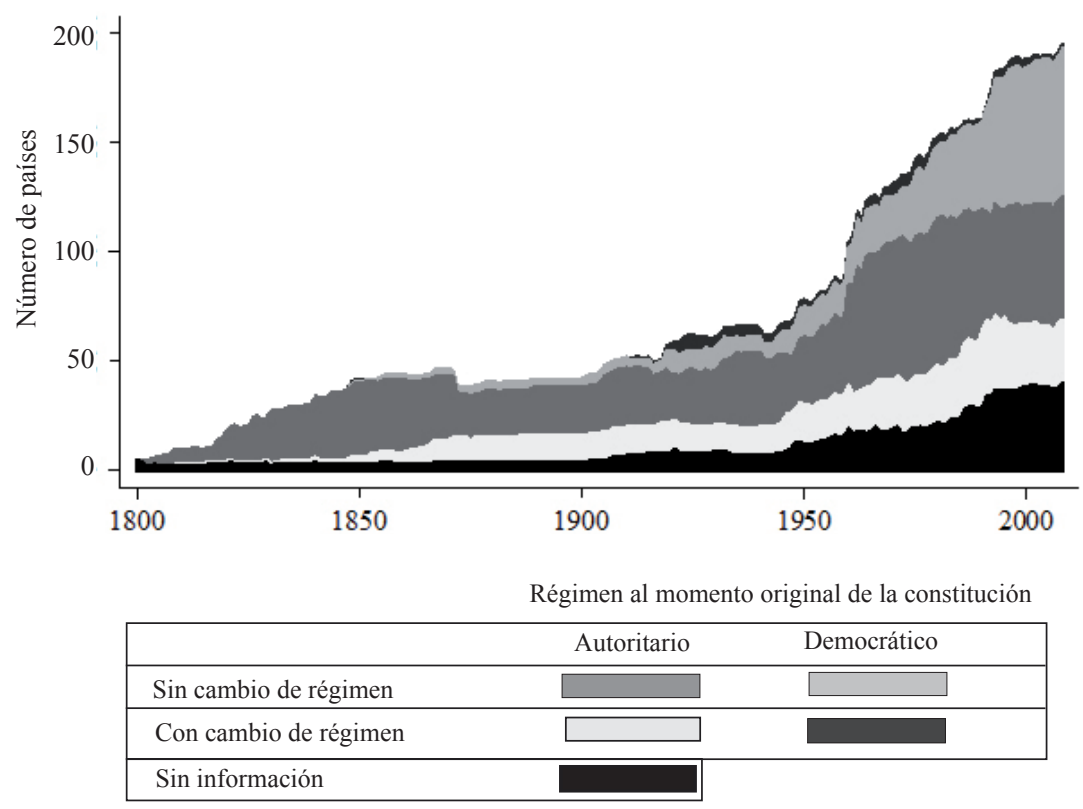


autoritaria transformadora es consciente de la superioridad de la soberanía popular y busca transferir poder a los dirigentes democráticos, pero sometidos a ciertas limitaciones. Busca además implementar algún mecanismo que garantice la operatividad de dichos límites.

La constitución de Turquía de 1982 nos provee de un ejemplo paradigmático ${ }^{13}$. Turquía tiene una larga tradición de política electoral, pero también ha experimentado azotes periódicos de dominación militar. Como lo observa Goldenziel, la Comisión de Venecia se refiere a Turquía como una "democracia tutelar", en la cual la democracia se encuentra atada por una alianza entre los militares, la burocracia y las $\operatorname{cortes}^{14}$. En la década de los ' 60 , la élite kemalista, que había gobernado en Turquía por décadas, estableció una corte constitucional, en parte para proteger los valores nucleares del secularismo de un revés por parte de los partidos religiosos. En la medida en que dichos partidos incrementaron su popularidad, la corte repetidamente los disolvió al mismo tiempo que se enfrascó en batallas con los poderes elegidos del gobierno $^{15}$.

La Constitución de 1982, adoptada durante uno de los períodos de gobierno militar directo, ilustra muchos de los temas del autoritarismo transformador. En la forma se trata de un documento democrático, que llama a elecciones. Como muchos documentos adoptados por militares, se refiere al rol esencial de la institución militar en la salvación de la nación, pero también habla en clave democrática: la palabra democracia es mencionada cinco veces. Se reafirman los valores del republicanismo y del secularismo como principios fundacionales imposibles de enmendar. Pero al mismo tiempo establece mecanismos claros de limitación a la política democrática. Éstos incluyen el Consejo de Seguridad Nacional, que ejerció como vigilante y sustitución del gabinete civil ${ }^{16}$. Además, la constitución contemplaba un umbral muy bajo para declarar un estado de excepción con la posibilidad de extensión indefinida. En particular, la Corte Constitucional de Turquía jugó un rol significativo en reforzar las restricciones de la Constitución de 1982, generando un límite estricto a la política democrática. La Corte, y la judicatura en ge-

${ }^{13}$ Goldenziel (2013:36-37) y Isiksel (2013:702-726).

14 Goldenziel (2013:35 n.143), citando a Ergun Ozbudun, European Commission for Democracy Through Law (Venice Commission).

15 Tezcur (2009:305-336).

${ }^{16}$ Isiksel (2013:717). 
neral, ha contribuido a desacelerar la transición a la democracia en momentos clave ${ }^{17}$. Para entender esto, señalaré sólo un ejemplo: en 2008, la Corte Constitucional resolvió que ciertas enmiendas legítimamente establecidas que revertían la prohibición de usar el pañuelo islámico en universidades eran inconstitucionales. Asimismo buscó prohibir el partido político del gobierno, el Partido de la Justicia y el Desarrollo, también conocido como AKP, por violar los principios del secularismo.

Desde 2003, sin embargo, se ha aprobado una serie de enmiendas que intentan reformar la constitución, a fin de reflejar el ascenso del $A K P$, como nuevo partido popular islámico. No obstante puede resultar difícil escapar a la influencia del documento. Muchos creen que el $A K P$ intentará reemplazar una forma de autoritarismo por otra, y que usará los mismos instrumentos que los militares. Como lo señala Isiksel, "el constitucionalismo autoritario insta a los nuevos proponentes a desarrollar los mismos malos hábitos que los salientes"18.

Otros ejemplos pueden incluir varias de las 18 constituciones adoptadas en Tailandia desde 1932. Tailandia representa un ambiente constitucional particularmente inestable, ya que los representantes en el gobierno han oscilado entre civiles corruptos y militares autoritarios. Los gobiernos militares en Tailandia, al menos desde la década de 1970, han aceptado formalmente la superioridad moral de la democracia, pero han intervenido ocasionalmente para remover a ciertos líderes o resolver una situación engrillada. Después de cada golpe de Estado, los militares parecen prometer, como suerte de rutina, un retorno al gobierno civil, pero al mismo tiempo redactan constituciones que se diferencian en un punto crucial de sus pares redactadas por civiles: la instalación de una cámara alta designada ${ }^{19}$. Esto es un reflejo de la desconfianza de la burocracia militar a los cargos políticos elegidos popularmente, y supone además la presencia de un veto a posibles cambios, lo que asegura que ciertos actores designados dispongan siempre de influencia en la política.

Más cerca de casa se encuentra la constitución de Panamá de 1972, promulgada por el general Torrijos luego de su golpe de Estado de 1968, la que lo designó como líder máximo de la revolución panameña, entregándole poderes extraordinarios que habrían de durar seis

\footnotetext{
${ }^{17}$ Bali (2012:235-320).

18 Isiksel (2013:725).

${ }^{19}$ Ginsburg (2009:83-105).
} 
años $^{20}$. Estos poderes expiraron en 1978 y, bajo presión de Estados Unidos, la Asamblea Nacional aprobó una serie de enmiendas, lo que generó un retorno a procesos democráticos durante los próximos años. Formalmente la constitución sigue vigente hoy, después de sobrevivir al ascenso y caída de Manuel Noriega.

Las constituciones autoritarias transformadoras poseen cierta semejanza con las especies del constitucionalismo transicional, como lo describe Teitel ${ }^{21}$. Pero se diferencian en que, mientras las segundas se concentran en el reconocimiento del pasado, las constituciones autoritarias transformadoras están típicamente diseñadas para blindar a sus autores de cualquier ejercicio de justicia futura. De este modo los variados mecanismos de inmunidad que encontramos en la constitución chilena de 1980 son un ejemplo paradigmático: las leyes que requieren una mayoría de 4/7 para su aprobación; el Tribunal Constitucional; el sistema electoral binominal y las garantías de impunidad.

Los documentos autoritarios pueden ser transformadores respecto del tipo de régimen, pero no respecto de la responsabilidad de los crímenes cometidos en el pasado. Si el constitucionalismo transicional, en la definición de Teitel, se preocupa de la reconciliación con el pasado, la constitución autoritaria transformadora oscurece el pasado. Como dice la expresión, se deben romper algunos huevos para hacer una omelet, y no queremos examinar ese proceso con demasiada atención. La lógica es que sin garantías de una participación en el futuro y alguna inmunidad para el autoritarismo transformador, la transición a la democracia es imposible. En este sentido se trata de una contra-categoría al constitucionalismo transicional de Teitel.

Desde un punto de vista normativo, las constituciones autoritarias transformadoras nos recuerdan que el atrincheramiento es un arma de doble filo. Los teóricos de la democracia lo ensalzan en la medida en que contribuye a la posibilidad de un gobierno democrático autodeterminado, pero al mismo tiempo puede servir para limitar el alcance de esta autodeterminación en aquellos casos en que se requieren negociaciones con el régimen anterior ${ }^{22}$. Este atrincheramiento, como lo explica el profesor Isiksel, puede "excluir la innovación, la adaptación y el aprendizaje institucional, magnificando las deficiencias, imperfecciones

\footnotetext{
${ }^{20}$ Constitución de Panamá, art. 277.

${ }^{21}$ Teitel (2000) y Teitel (2011).

22 Isiksel (2013:708).
} 
e incluso las injusticias de la norma en cuestión"23. Usar la técnica del constitucionalismo para desacelerar el proceso político es una estrategia que se remonta al menos a los padres fundadores, pero los fines para los cuales esta herramienta se utiliza son tan variados como las circunstancias de nacimiento de las constituciones.

\section{Características de las constituciones autoritarias transformadoras}

En un reciente capítulo escrito en coautoría con mis colegas Zachary Elkins y James Melton proveemos alguna evidencia descriptiva sobre esta categoría de casos y el modo en que se diferencian de las constituciones autoritarias "puras" 24 . Realizamos un análisis de regresión relativo al contenido de constituciones escritas, evaluando: (1) las diferencias entre las constituciones democráticas y autoritarias, y (2) las diferencias entre las constituciones autoritarias que experimentan una transición a la democracia y aquellas que no lo hacen. También incluimos distintas variables para controlar los factores generalmente asociados con los contenidos de una constitución (región, el tipo previo de constitución del país y época de la redacción). El análisis muestra que las constituciones autoritarias que eventualmente giran hacia la democracia tienen un parecido mucho mayor con las constituciones democráticas que con las constituciones autoritarias "puras". En varias dimensiones - derechos, independencia judicial y otras materias específicas - las constituciones autoritarias que experimentan una transición a la democracia en algún punto de su vida no son diferentes en lo sustantivo a las constituciones escritas por demócratas, al menos en lo que respecta a los atributos constitucionales analizados.

Las constituciones autoritarias transformadoras, entonces, están más cerca de las constituciones democráticas que lo que uno esperaría. Y en este sentido se distancian sistemáticamente de las constituciones autoritarias "puras". Nuestra evidencia apoya de alguna forma la observación de Steven Levitsky y Lucan Way, según la cual las instituciones formales de la categoría que ellos llaman "autoritarias electorales" son similares a aquellas de las democracias. Pero aquí

\footnotetext{
${ }^{23}$ Ibídem.

${ }^{24}$ Elkins et al. (2013).
} 
introducimos una dimensión temporal al análisis: esperamos observar instituciones específicas para controlar el sistema político bajo la constitución.

\section{EI caso de Chile}

Chile parece encajar bien en este paradigma. La Junta del General Pinochet aprobó la Constitución de 1980 con la mirada puesta en el retorno al poder de las fuerzas democráticas a través de una transición ordenada. Esta constitución aseguró derechos de propiedad (una preocupación central del derecho chileno), prohibió partidos políticos, le entregó a la institución militar un veto de facto traducido en la facultad de nombrar senadores, y estableció, entre otras instituciones, un Tribunal Constitucional facultado para revisar la legislación previamente a su promulgación, como un resguardo a la conducta de los actores en el futuro. Pero más allá de estos aspectos de veto, la constitución chilena muestra un aspecto bastante democrático en la forma. Contiene 43 derechos de un índice de 116 que hemos analizado, lo que importa un aumento de 16 derechos respecto de su predecesora, la Constitución de 1925, y 11 menos que el promedio de todas las constituciones. Establece elecciones luego de cierto período. Y configura el principio de independencia judicial, entre otras características vinculadas a la democracia electoral. Los aspectos distintivos de la Constitución de 1980 son aquellos que regulan el tiempo y los procesos antes que la sustancia.

Analistas señalan que la judicatura chilena como un todo jugó un rol generalmente regresivo en la democratización. En primer lugar, bajo el mito de la mantención de un rol apolítico, evitó interferir en la dictadura $^{25}$. Luego, durante la primera década posterior a Pinochet, fue fundamentalmente un obstáculo al cambio político y contribuyó a solidificar el acomodo constitucional de una amnistía a favor de los dictadores, así como una fuerte protección de derechos de propiedad. También bloqueó reformas judiciales, manteniendo un control jerárquico sobre los tribunales de justicia inferiores a la Corte Suprema. Finalmente, a principios de los años 2000 los jueces chilenos comenzaron a relativizar los efectos de la ley de amnistía, una de las bases de la transición de Pinochet. Los tribunales fueron, entonces, durante mucho

${ }^{25}$ Hilbink (2007). 
tiempo un efectivo mecanismo de refuerzo inferior de la amnistía y desempeñaron un papel crucial para la constitución autoritaria transformadora, un garante.

Al mismo tiempo, ciertas instituciones jurídicas sí jugaron un rol en constreñir a la Junta. El importante estudio sobre el Tribunal Constitucional de Robert Barros afirma que la tradición legalista del país sirvió para hacer de las instituciones jurídicas una solución atractiva a problemas de coordinación internos del régimen ${ }^{26}$. Durante los primeros años de su existencia, el Tribunal Constitucional fue complaciente y reconocía los dictámenes del régimen como constitucionales ${ }^{27}$. Sin embargo, en septiembre de 1985, el Tribunal emitió una decisión que tuvo profundas implicancias para la estructura de la competencia política. La constitución requería que se llevara a cabo un plebiscito para aprobar o rechazar al primer presidente civil, nominado por los militares. La respectiva ley orgánica constitucional había propuesto que este referéndum fuera supervisado por una corte electoral ad hoc. El Tribunal, sin embargo, sostuvo que el plebiscito requería una estructura completa de supervisión electoral, lo que incluía una lista de votantes y un conteo independiente. Esto redujo las posibilidades de los militares de arreglar el plebiscito.

Ésta fue en gran medida una decisión de refuerzo constitucional. Indujo a la oposición a participar en lugar de boicotear el plebiscito. Los militares, por su parte, pueden haberse decepcionado ante esta decisión, pero considerando la inversión hecha en la estructura completa del esquema constitucional, quizás estuvieron reticentes a descartarla de plano. Además, los militares reconocieron estas decisiones en parte porque no estaban internamente unificados ${ }^{28}$. El Tribunal entonces prosiguió con esta serie de decisiones en virtud de las cuales exigió a la Junta permitir una estructura justa para el proceso político, lo que incluía un libre e igualitario acceso a los medios de comunicación y reglas sobre organizaciones políticas ${ }^{29}$. El proceso constriñó en último término a la Junta. La oposición ganó el plebiscito, frente al asombro de Pinochet, y pavimentó así el retorno a la democracia. Esto ilustra cómo las cortes, incluso en dictadura, son capaces de ejercer cierta autonomía

\footnotetext{
${ }^{26}$ Barros (2002).

${ }^{27}$ Ibídem, p. 213.

${ }^{28}$ Ibídem, p. 216.

${ }^{29}$ Ibídem, p. 214.
} 
y permitir espacios a las fuerzas opositoras. La institución del garante se convirtió en un aparato creíble de compromiso, restringiendo tanto a los dictadores como a los demócratas.

\section{IV. ¿Evolución o revolución? Transformando la constitución transformadora en la actualidad}

Todas las constituciones necesitan ajustes en el tiempo, en la medida en que el mundo mismo experimenta cambios. Nacen nuevas coaliciones políticas y movimientos sociales, se generan nuevas circunstancias económicas y el entorno internacional se transforma constantemente. Resulta por tanto imposible imaginar una constitución capaz de mantenerse completamente imperturbable.

Existen, por supuesto, muchas y variadas modalidades de cambio constitucional. Las constituciones pueden ser reemplazadas por completo: esto ocurre con mucho mayor frecuencia de la que uno esperaría. Las constituciones pueden ser modificadas con reformas formales (que en el caso de Chile van por los cientos), lo que parece ser lo más ob$v \mathrm{v}^{30}$. Con mucho mayor frecuencia, las constituciones se transforman por medio de la interpretación que desarrollan las cortes y otros actores políticos, por cuanto el significado cambia a partir de un texto que no se altera; en ciertos casos esto incluso puede conllevar giros no buscados en la práctica o en el significado ${ }^{31}$.

En el nivel más simple, podríamos tratar estos distintos modos formales e informales de interpretación como simples sustituciones. Esto es, podríamos simplemente elegir entre reemplazar toda la constitución de una vez o bien reemplazarla paulatinamente por medio de una serie de enmiendas que mantengan la continuidad formal, pero que cambien el texto por completo. Sabemos, después de todo, que las constituciones pueden sufrir transformaciones radicales por medio de enmiendas. La constitución argentina de 1853 se mantiene nominalmente vigente hoy, a pesar de que resulta irreconocible en muchos aspectos. Para usar algunos ejemplos de mi propio país, California aprobó 130

${ }^{30}$ Nuestro estudio muestra que el $92 \%$ de las constituciones históricas, así como todas aquellas vigentes en la actualidad, incluyen algún procedimiento de reforma.

31 Jellinek (1906). Recientemente revivido en el interesante trabajo de Julian Arato. Véase e.g. Arato (2012:349-388) y Arato (2013:289-357). 
enmiendas a su constitución estatal en 1966; Carolina del Sur aprobó 200 entre 1971 y 1973. El texto de estos documentos en la actualidad guarda muy poca similitud con aquel que fue inicialmente adoptado.

Más aún, sabemos también que incluso aquellos cambios constitucionales marcados por rupturas formales pueden asegurar una buena cuota de continuidad. La herencia puede persistir y las constituciones pueden tener vida después de su completo reemplazo. Existe, como mis colegas y yo lo mostramos en nuestro libro de 2009, una notable similitud serial en el contenido del texto de las constituciones de un mismo país (véase figura $\left.n^{\circ} 4\right)^{32}$. La figura documenta mediciones de similitud diádica, que nos permiten comparaciones entre dos textos constitucionales cualesquiera, a través del tiempo y en varios países. La figura muestra que las constituciones adoptadas en el contexto histórico de un mismo país tienden a ser más similares entre sí que respecto de otra constitución seleccionada al azar de un set completo con todas las constituciones del mundo. En resumen, la distinción entre reemplazo y enmienda puede no ser tan clara como uno podría imaginarlo o esperarlo.

Entonces, ¿son enmienda y reemplazo simples sustituciones? La pregunta es a la vez conceptual y empírica. Conceptualmente, la pregunta apunta a si existe efectivamente una forma de identidad en el período de vida de una constitución, de modo que se aprecie una continuidad en el objeto a considerar. La cuestión se asemeja a las discusiones filosóficas sobre la continuidad de vida humana. Como se pregunta Derek Parfit, si un cirujano, durante un largo período de tiempo, extrae parte del cerebro de una persona y lo reemplaza con una réplica exacta, y así prosigue hasta que no quede nada del tejido original, ¿seguiría siendo el mismo cerebro? ${ }^{33}$ Parfit usa el punto para afirmar que la continuidad física no es necesaria para la continuidad de la identidad humana, y los filósofos han usado esto como punto de partida para teorizar sobre asuntos de vida o muerte humana ${ }^{34}$. Por analogía, si se enmienda cada norma de una constitución, una a la vez, a través de un período de tiempo, ¿se trata de la misma constitución?

Cualquiera sea la visión que se sostenga de la filosofía de la mente, creo que la respuesta es afirmativa en lo que respecta a las constituciones. Mi respuesta tiene quizás más sustento empírico que con-

\footnotetext{
${ }^{32}$ Elkins et al. (2009).

33 Parfit (1984:474).

${ }^{34}$ McMahan (2002).
} 

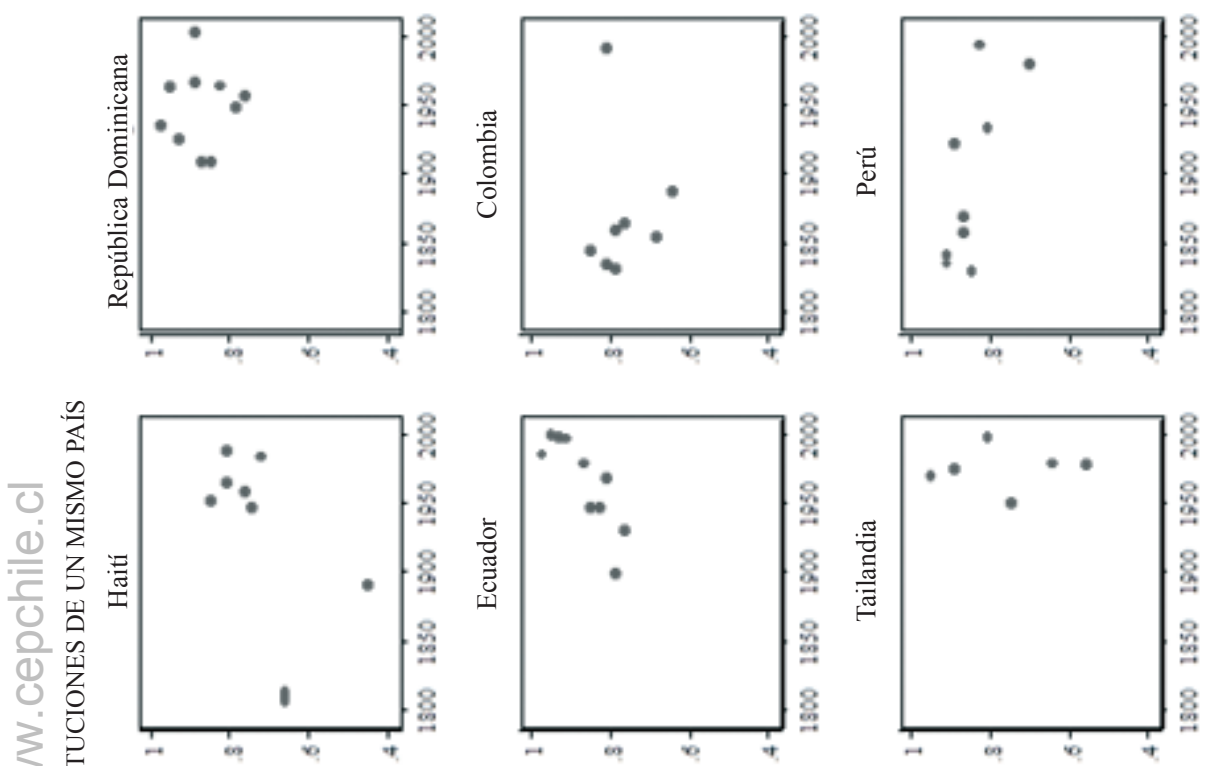

送
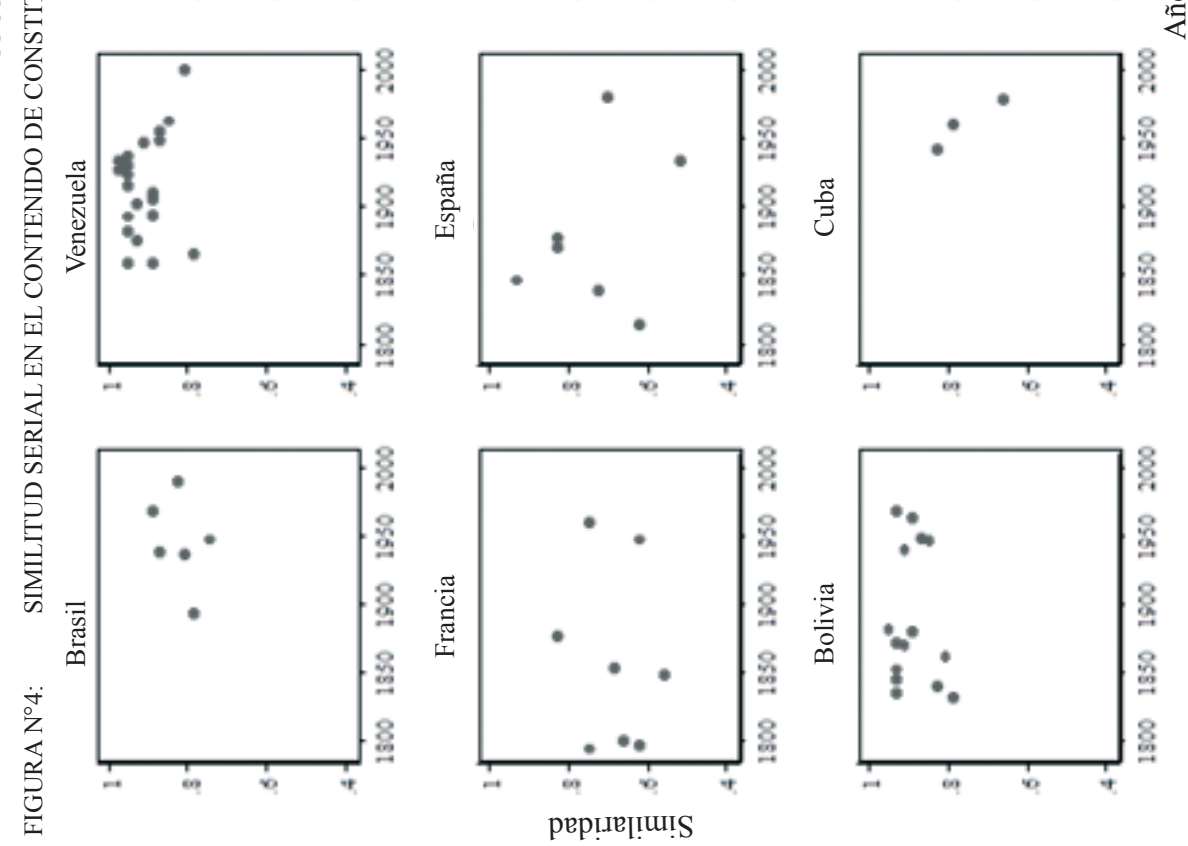
ceptual. Las constituciones, como los cuerpos humanos, son sistemas de instituciones que trabajan en conjunto y afectan los cursos de acción subsecuentes. Las constituciones le dan forma al entorno político, el cual da origen a actores particulares en posición de modificar de modo subsecuente las reglas del juego. Deben tratarse como biografías antes que como simples momentos estáticos. Así, cambiar cada pieza a lo largo de varios años mantendría de todas formas la continuidad de la identidad constitucional.

En lo empírico, observamos en un estudio de 2009 que parece haber costos significativos en el cambio constitucional. Observamos que varios bienes como el crecimiento, la democracia y la resolución pacífica de conflictos se incrementan a la par con la edad de las constituciones, en promedio ${ }^{35}$. En síntesis, hay razones para creer que la continuidad formal importa en relación con varios índices de éxito: legitimidad, funcionamiento institucional y la producción de bienes públicos.

Como comentario aparte, puedo notar también que asumir que las circunstancias de redacción marcarán de modo inevitable y permanente el documento subsecuente tiene alguna relación con los conceptos normativos de la "intención original". Los académicos de derecho constitucional estadounidense debaten —eternamente - sobre la intención de los fundadores en la interpretación de la constitución hoy, más de dos siglos después. Por mi parte, no soy imparcial a los puntos de vista de aquellos que son etiquetados como constitucionalistas vivientes, que enfatizan el proceso continuo de recrear la constitución en cada era $^{36}$. Si podemos fundamentalmente ajustar un texto escrito en circunstancias muy distintas, entonces la transformación constitucional es posible, y no deberían preocuparnos mucho las circunstancias fundacionales. La identidad que compartimos con los fundadores puede tener un poder simbólico, pero no exige un poder jurídico.

Todo esto, por cierto, no significa que resulta deseable conservar la constitución original en toda circunstancia. Seguramente, en ciertos contextos, la marca asociada con el nacimiento de la constitución es suficientemente poderosa para hacer del reemplazo algo deseable. Revisemos brevemente argumentos favorables a la revolución y a la evolución en estas circunstancias.

\footnotetext{
${ }^{35}$ Elkins et al. (2009).

${ }^{36}$ Strauss (2010).
} 


\section{IV.a. El argumento para la revolución o semi-revolución}

¿Cuándo debiera redactarse una constitución completamente nueva? Resulta evidente que al hacerlo se marca un quiebre simbólico que en ciertos casos puede ser deseable, en particular después de un cambio político radical. Algo así como una de cada cinco transiciones, ya sea de democracia a dictadura o viceversa, está marcada por la adopción de una nueva constitución. Estos cambios de régimen motivan la búsqueda por un nuevo momento fundacional que oriente la actividad política subsecuente.

El cambio de régimen no es por tanto condición necesaria ni suficiente para el cambio constitucional. En ocasiones regímenes muy estables adoptan una nueva constitución: Suecia re-escribió completamente su constitución en 1974, tanto para consolidar una gran cantidad de enmiendas que habían tenido lugar desde la adopción de la versión previa en 1809, como para implementar un parlamento unicameral en vez de uno bicameral. Esto puede verse como un proyecto más bien técnico, sin un elemento simbólico obvio, sin embargo, muestra que una crisis no es un prerrequisito para el cambio constitucional.

Mucha literatura reciente ha puesto el énfasis en la importancia de la identidad constitucional ${ }^{37}$. Esta línea de trabajo enfatiza el rol de la constitución en la definición del pueblo, en el proceso de lidiar con el pasado y articular una visión para el futuro. Los procesos de confección de constituciones pueden proveernos de una oportunidad para involucrar a la población en un proyecto deliberativo que puede tener efectos saludables en la política. Por esta razón, se ha convertido en norma para la redacción de nuevas constituciones en Estados en proceso de reestructuración que la población sea consultada, y sea la que apruebe la constitución. El proyecto de confección de una constitución puede ayudar a una nación a concretizar el sentido de sí misma.

Siguiendo a Hegel y Lacan, Michel Rosenfeld describe un proceso de tres etapas de incorporación del pasado ${ }^{38}$. Primero corresponde la fase de la pura negación, que supone un repudio total al pasado; la constitución se muestra hostil a su historia ${ }^{39}$. Luego corresponde el reconocimiento de que toda nación tiene su pasado. La identidad constitu-

\footnotetext{
${ }^{37}$ Kommers et al. (2009).

38 Rosenfeld (2009).

${ }^{39}$ Véase también Scheppele (2008:1389).
} 
cional no puede formarse en el vacío, de modo que el proyecto de producción constitucional debe identificar y seleccionar algunos elementos del pasado inicialmente descartados. La tercera etapa es la negación de la negación, que supone la reestructuración de estos elementos en un todo coherente.

Este proyecto de reforma del pasado a través de la producción constitucional tiene sus atractivos. Para el Chile actual, negar la negación supondría, no una regresión a la realidad pre-Pinochet, sino incorporar los elementos difusos de su historia política reciente a un todo coherente. Y quiebres como éstos pueden alcanzarse sin perder continuidad jurídica con el pasado. Andrew Arato, por ejemplo, ha formulado un modelo de producción constitucional "post soberano", en el que la creación de un nuevo orden tras la caída de un dictador se logra dentro de los límites de la constitución previa, aun cuando dicho documento pueda estar histórica y normativamente manchado ${ }^{40}$. Una constitución vieja puede facilitar el nacimiento de un nuevo amanecer, simplemente sosteniendo el proceso de producción constitucional.

Éstos son entonces los argumentos para una nueva constitución para Chile en la actualidad. Lo simbólico del pasado, los déficits técnicos de un documento muy enmendado y los constreñimientos específicos a la regla de la mayoría que quedaron como legados del gobierno autoritario favorecen un nuevo comienzo, que puede alcanzarse invocando la potestad constituyente.

\section{IV.b. El argumento para la evolución}

Edmund Burke alguna vez escribió que un "gobierno que gobierna bien puede reclamar legítimamente obediencia de sus ciudadanos, aun cuando en el origen haya sido ilegítimo". ${ }^{41}$ En una línea burkiana, los proponentes de la evolución enfatizan las virtudes del cambio gradual en las constituciones. Una manera general de aproximarse al problema es a través del análisis costo-beneficio. El cambio constitucional es costoso y

\footnotetext{
${ }^{40}$ Arato (2009:5-7). Este autor distingue entre legitimidad y legalidad. Por ejemplo, la constitución de Estados Unidos fue creada a través de una ruptura legal, pero con continua legitimidad. Para muchos la constitución japonesa de post-guerra se creó en una ruptura en la legitimación, pero con una continuidad legal.

$$
{ }^{41} \text { Canavan (1987:163-176). }
$$
}


la revisión total lo es todavía más. Toma tiempo y energía involucrarse en la deliberación requerida para llegar a una enmienda. Además, existen riesgos asociados a una enmienda total. Esto es así porque la modificación de muchas instituciones abre demasiados espacios de deliberación; más cuestiones pueden negociarse, y los resultados finales son más inciertos. Mientras más amplio sea el espectro de negociación, más difícil será completarla, y menos predecible ex ante. Así, se podría argumentar que en la línea burkiana es mejor hacer cambios a instituciones específicas, una tras otra, por medio de enmiendas constitucionales.

Existen algunos casos prominentes de evolución constitucional lejos de los regímenes autoritarios. Indonesia es un ejemplo muy importante que ha recibido poca atención en la literatura ${ }^{42}$. Más de una década después de la caída de Suharto, Indonesia es ampliamente considerada un ejemplo exitoso de democratización. Esto se logró a través de dos series de enmiendas a la Constitución de 1945, la cual retuvo una legitimidad simbólica importante asociada a la independencia del país. Indonesia es un país muy diverso, que ha enfrentado varios movimientos secesionistas, además de los efectos de décadas de gobierno militar. Podría decirse que era un país con bajas posibilidades de lograr una transición constitucional. Pero en vez de dar forma a una nueva constitución a través de un quiebre marcado, Indonesia optó por adoptar enmiendas constitucionales en cuatro etapas entre 1999 y 2002. Estas enmiendas transformaron completamente el sistema político. El proceso desafió los convencionalismos y su sabiduría en muchos sentidos. En primer lugar, Indonesia sostuvo elecciones antes de iniciar los cambios constitucionales y luego permitió al poder legislativo, en vez de una asamblea constituyente, llevar adelante el trabajo. En segundo lugar, el proceso de enmienda se llevó adelante por gente interna, con miembros del partido político de Suharto en posiciones clave. Una combinación de casualidad, suerte e ingenioso diseño institucional, permitió a Indonesia transformar su elaborado y complejo sistema de divisiones sociales en un sistema multipartidista. Cuando todo estaba listo para que el sistema se saliera de control luego de la acusación a Abdurrahman Wahid en 2001, el país reaccionó con la creación de una corte constitucional para resolver este tipo de disputas en el futuro. Esto representó un ajuste institucional crucial.

${ }^{42}$ Horowitz (2013). 
En Taiwán, las reformas constitucionales de los años 90 y principios de los 2000 también representaron una serie de reformas graduales que lidiaron con muchos de los efectos del régimen autoritario. Antes de la transición a la democracia, Taiwán era gobernado por un régimen unipartidista elegido a fines de los años 40. Este grupo mantuvo poder sobre la población nativa taiwanesa, penosamente reprimida. Cuando comenzó la democratización en serio bajo el presidente Lee Teng-hui a fines de los años 80, una limitación importante era la República Popular China, que podría mirar la nueva constitución como una declaración de independencia y fuente de agresión. De esta manera los demócratas procedieron con una serie de enmiendas constitucionales que transformaron profundamente tanto la estructura de gobierno como la corte constitucional, lo que a su vez sirvió para despejar muchos de los resabios del régimen autoritario. Todo esto se logró de modo gradual, sin provocar a enemigos internos o externos que arruinaran el proceso.

En suma, existe al menos evidencia anecdótica que sugiere que no es necesaria una reforma radical para llevar adelante cambios profundos al sistema político, y que un esquema constitucional que opera durante una dictadura puede de hecho sobrevivir a la democracia. La evolución ha sido la modalidad de Chile a la fecha, incluyendo coyunturas fundamentales en 1989 (la Ley 18.825 modificó 54 normas), en 1997 (21 normas cambiaron en tres enmiendas separadas) y en 2005 (con 12 enmiendas y más de 50 normas modificadas). De nuevo, nada de esto significa que la evolución es la estrategia obligada. Más bien, muestra que es una opción.

\section{V. ¿Cómo reformar? Asamblea constituyente versus potestad legislativa}

La asamblea constituyente y la potestad legislativa son dos de las más comunes modalidades de reforma constitucional. En un estudio de 2009 encontramos que de aproximadamente 400 procesos de diseño constitucional, la asamblea constituyente fue utilizada en 143 casos, usualmente como actor solitario. Pero hay muchas variantes y pocas prácticas consistentes. Existen muchas formas híbridas.

La asamblea constituyente de India, por ejemplo, decidió ejercer como un parlamento ordinario de modo previo a la adopción de la constitución en 1949. Esto es un ejemplo de lo que la literatura llama una asamblea constituyente legislativa, que conduce simultáneamente la acti- 
vidad legislativa diaria de un parlamento ordinario mientras continúa funcionando además como asamblea constituyente. Otro ejemplo viene de Panamá, cuya constitución promulgada en marzo de 1946 estipulaba que la asamblea constituyente nacional se convertiría ella misma en la asamblea legislativa con miembros ejerciendo hasta el 30 de septiembre de 1948. La asamblea constituyente de El Salvador hizo lo mismo en 1983.

Gran parte del debate en la literatura ha seguido el innovador trabajo de Jon Elster en el que afirma que el congreso ordinario no debería redactar constituciones ${ }^{43}$. Elster divide en tres los motivos de la creación constitucional: razones, pasiones e intereses. Aunque reconoce que todos juegan un rol, sostiene que el diseño óptimo de un procedimiento de creación constitucional maximizará el rol de las razones en relación con el autointerés y las pasiones populares. Las legislaturas, sugiere, son inferiores a las asambleas constituyentes especiales que se involucran únicamente en la creación constitucional. Esto es así, él cree, porque los legisladores tienden hacia un engrandecimiento institucional, a concentrarse menos en la tarea y a ser víctimas de la dependencia del contexto, en el que el nivel de legislatura ordinaria ejerce influencia sobre el nivel constitucional "superior". Otro argumento sostiene que los cuerpos legislativos tenderán a poner demasiado detalle en el documento, pues no manejan la distinción entre normas de primer orden y cuestiones de política ordinaria. La Constitución de 1988 de Brasil se presenta como el mejor retrato de este punto $^{44}$.

Trabajando con otros coautores, generamos un par de trabajos es que cuestionamos estas asunciones. Concluimos que, sin perjuicio de las intuiciones de Elster, existían pocas diferencias sistemáticas entre aquellas constituciones producidas por legislaturas y aquellas por asambleas ${ }^{45}$. Sí encontramos evidencia de engrandecimiento institucional en constituciones redactadas en procesos dominados por el ejecutivo, otra de las conjeturas de Elster. Sin embargo, en lo que respecta al parlamento frente a la asamblea, no se apreciaron diferencias en cuanto a la longitud, poder legislativo o número de derechos.

43 "Para reducir el espectro de interés institucional, las constituciones deben ser escritas por asambleas especialmente convenidas, y no por cuerpos que actúen también como legisladores ordinarios. Tampoco al poder legislativo debe entregársele un lugar central en la ratificación.” Elster (1998:117). Elster mantiene esta tesis en su trabajo más reciente: Elster (2013), capítulo cuarto.

${ }^{44}$ Rosenn (1990:773, 775-777).

${ }^{45}$ Ginsburg et al. (2009a) y (2009b). 
La asamblea implica el ejercicio del pouvoir constituent — del poder constituyente-, y así en ciertas circunstancias puede excederse en sus tareas de ejercer libremente este poder de creación. En América Latina, la doctrina del poder constituyente, en efecto, a veces es particularmente amplia. David Landau (2013) ha afirmado que el uso de asambleas constituyentes en Venezuela y Bolivia resultó altamente problemático por el riesgo de que las asambleas ignoraran cualquier constreñimiento de jerarquía superior introducido en el proceso ${ }^{46}$. El río puede desbordarse. Por ejemplo, en Venezuela en 1999, el comandante Hugo Chávez tomó el control de la asamblea constituyente con el fin de consolidar el control sobre todas las instituciones independientes, incluyendo la Corte Suprema que logró resistir brevemente. Intervino así las reglas electorales de modo que, con el $60 \%$ de los votos, su partido obtuvo el $95 \%$ de los cupos en la asamblea. Y lo hizo sin ninguna continuidad jurídica: la constitución anterior no disponía la posibilidad de una asamblea constituyente. Eventualmente, la Corte, utilizando la doctrina del "poder constituyente originario", favoreció esta acción. Mientras intentaba poner límites al ejercicio de este poder, Chávez la ignoraba, hasta llegar eventualmente a apretarla, lo que llevó a un académico a describir que la Corte había "firmado su propia sentencia de muerte" 47 .

La asamblea constituyente de Bolivia sí se mantuvo dentro de los límites, pero sólo después de violentas protestas que pusieron en riesgo la estabilidad del país. El partido de Evo Morales intentó invocar la potestad constituyente originaria. El esfuerzo de Bolivia fue inducido en un intento de incluir fuerzas de la sociedad boliviana excluidas por mucho tiempo, pero fue también un proceso altamente polarizado en un ambiente de débil institucionalidad. En cierto punto, estallaron violentos disturbios, lo que tuvo como consecuencias cientos de heridos y tres muertos. Esto es un recordatorio de que el proceso constituyente no siempre se muestra como una oportunidad para el consenso sino que puede representar momentos de trauma político. Como lo afirma Landau, precisamente porque las asambleas constituyentes pueden ser vistas como instancias de legislación superior, pueden ser difíciles de sujetar.

\footnotetext{
${ }^{46}$ Landau (2013:923-980).

${ }^{47}$ Ibídem, p. 948.
} 
Esto no significa que las asambleas constituyentes causen inestabilidad siempre y en todos los casos. La experiencia de Colombia en 1991 fue que, en el contexto de un pacto debilitado y con el surgimiento de nuevos partidos, se realizó una asamblea constituyente, pero sin el dominio de ningún partido. La asamblea sirvió como vehículo para la reestructuración de la política colombiana hacia un sistema competitivo ${ }^{48}$. Lo que esto sugiere es que es muy difícil realizar predicciones simplistas basándose en la elección entre una asamblea constituyente o la potestad legislativa.

Otra posibilidad que Chile puede considerar es la de una conferencia nacional para efectos de discutir el esquema de reforma constitucional, sin necesariamente producir un texto específico. Estos son cuerpos separados de la legislatura ordinaria, y cuya autoridad no deriva de ésta. Pueden llegar a ser bastante amplias. Por ejemplo, la conferencia nacional de Mali que tuvo lugar en 1991 contó con aproximadamente 1.800 delegados. Delegaciones numerosas tienden a ser más inclusivas o representativas, y ello reduce el riesgo de autorreparto institucional. El análisis de Jennifer Widner sugiere que estas conferencias son más susceptibles de incorporar extensas franjas de la sociedad civil al proceso de diseño constitucional, en comparación con la legislatura ordinaria ${ }^{49}$.

Existen muy pocas reglas básicas para el diseño de una conferencia nacional. Puede ser usada para generar nuevas ideas, promover sugerencias o incluso decisiones vinculantes para el futuro. El contexto de Chile podría permitir incorporar una variedad de fuerzas sociales, sin las consecuencias potencialmente dañinas de la alienación de los partidos e instituciones ya existentes, los cuales en general funcionan admirablemente bien. Ahora nos dedicamos al análisis de estos riesgos.

\section{V.a. El rol de los partidos y de los sistemas electorales}

Los casos de Venezuela y Bolivia representan instancias en las cuales la asamblea constituyente se invocó a causa de los cambios producidos en el sistema de partidos. Pactos de larga data comenzaron a quebrarse, al tiempo que se levantaron partidos insurgentes en representación de nuevas circunscripciones. Esto hacía que el proceso

\footnotetext{
${ }^{48}$ Ibídem, p. 962.

${ }^{49}$ Widner (2005:503-518).
} 
constitucional fuera fácilmente politizado, y que conflictos políticos que podrían considerarse parte de la política ordinaria terminaran escalando al nivel constitucional. El sistema de partidos interactuó con el proceso constitucional de modo tal que cerró las posibilidades de una deliberación tranquila.

En otras situaciones, los partidos políticos pueden jugar un rol positivo en la reforma constitucional. Un peligro que hay que evitar, en cualquier caso, es la tentación de pasar por el lado del sistema de partidos políticos. La experiencia de Islandia nos muestra cómo los partidos terminaron bloqueando desde abajo una iniciativa radical $^{50}$. El notable experimento de Islandia comenzó con la severa crisis financiera de 2008, que causó el colapso del sistema bancario del país. En los eventos posteriores, una corriente de apoyo al cambio constitucional derivó en la aprobación, con un apoyo avasallador, de un estatuto parlamentario para guiar el proceso. A continuación se conformó un grupo de 950 ciudadanos seleccionados al azar para generar ideas de reforma constitucional. Luego, en el otoño de 2010, veinticinco islandeses ordinarios fueron elegidos de un campo de más de 500 para servir en un consejo constitucional destinado a formular la nueva constitución. Los consejeros buscaron una amplia participación y los islandeses tuvieron la oportunidad de seguir las decisiones del consejo y contribuir con sugerencias a través de internet usando una página de Facebook. Existió un proceso reiterado de borradores y comentarios, lo que introdujo modificaciones al proyecto propuesto. Es improbable que podamos encontrar otro proceso de creación constitucional en el que el público general haya tenido este nivel de participación directa.

El proyecto final que produjo la comisión expandía de modo considerable la democracia directa, permitiendo al público involucrarse en una gobernanza continua. Incluyó una afirmación del principio "una persona, un voto", con un sistema electoral complejo. El proyecto también establecía, controversialmente, que los recursos naturales del país eran propiedad del Estado, con la posibilidad de licitaciones de corto plazo pero no de enajenación a privados. Esta norma buscaba revertir la privatización de licencias de pesca que tuvo lugar en el país a principios de los años 90, un proceso que para algunos restableció el vigor de la industria pesquera, pero que al mismo tiempo contribuyó a generar

${ }^{50}$ Ginsburg (2013). 
disparidades crecientes en la riqueza. El proyecto fue la base de un referéndum que tuvo lugar en octubre de 2012 y que apoyaba los cambios propuestos. Bajo la constitución vigente, la reforma requería un voto en dos legislaturas sucesivas, de modo que la ciudadanía participaba de modo puramente consultivo. Pero el momento sugería que podíamos estar en presencia de un raro ejemplo de demandas exitosas de cambio constitucional generadas desde abajo.

El proceso giró finalmente hacia el parlamento, que debía generar una carta definitiva. Aquí es donde las cosas se tornaron complicadas. Hubo oposición de partidos y algunos comenzaron a atacar vigorosamente las propuestas; el consejo de la Comisión de Venecia emitió un reporte que identificaba algunos puntos preocupantes del proyecto; $\mathrm{y}$ el parlamento comenzó a experimentar y modificar la carta. Esa semana el parlamento aprobó una ley sin las normas claves del anteproyecto ciudadano, al mismo tiempo que elevó el quórum de reforma constitucional a $2 / 3$ más el $40 \%$ del voto popular. Esto se hizo en vísperas de elecciones respecto de las cuales había mucha expectativa de una victoria de la oposición.

En suma, los partidos políticos, en la medida en que sean estables, no pueden dejarse a un lado en un proceso de reforma. Hacerlo supone correr el riesgo de un descarrilamiento en una etapa posterior. Sólo en aquellas situaciones en que el orden político existente se encuentra completamente desacreditado puede resultar efectiva la estrategia de pasar por el lado de los políticos.

\section{V.b. El rol de las cortes como guardianes}

Las cortes pueden desempeñar un papel muy importante como guardianes del proceso de creación constitucional. Se trata de un caso de restricción de orden superior. Es obvio que esta opción está más al alcance allí donde las cortes tienen un buen registro y cuentan con la confianza de los actores del proceso político.

El ejemplo más famoso de protección judicial de un proceso de creación constitucional es el de la Corte Constitucional de Sudáfrica durante el período de la constitución interina (1993-1996). Dicha constitución había establecido un cuerpo de principios básicos para guiar la elaboración de la constitución definitiva por la asamblea constituyente. Pero la constitución final debía certificarse por la Corte Constitucional 
para comprobar que se conformaba con la lista de principios constitucionales establecidos en el documento anterior. Los principios incluían tanto conceptos generales como provisiones específicas que eran importantes para ciertos grupos, como es el caso de la autodeterminación y la descentralización regional. En dicha ocasión, la Corte Constitucional rechazó varias provisiones de la constitución, como lo solicitaron varios de los principales partidos políticos ${ }^{51}$. La Corte aportó lineamientos para revisar el texto de manera que se respetaran los principios. Luego de una revisión, la Corte participó de una segunda ronda de certificación, y aprobó el proyecto. De forma también interesante, la Corte jugó un rol en la certificación de constituciones provinciales, cuando rechazó una de ellas, la de Kwa Zulu Natal.

Otro ejemplo lo encontramos en Kenia. Durante el largo período de evolución constitucional que tuvo lugar en Kenia desde el régimen unipartidista de Moi en la primera década de este siglo, las cortes tuvieron alguna participación. Desde 2001 hasta 2005, una conferencia y luego el parlamento produjeron una serie de borradores. Hubo poco acuerdo en cuestiones tan básicas como el tipo de gobierno. En 2004, la Alta Corte de Kenia en la decisión Timothy Njoya \& Others v. CKRC and the National Constitutional Conference sostuvo que la constitución no podía ser reemplazada sin un referéndum. El proceso ordinario de reforma detallado en la sección 47 de la constitución permitía enmiendas, pero no un reemplazo completo. En otras palabras, se debía regresar a la fuente del pouvoir constituent para efectos de avanzar con reformas de cierta magnitud. Esto es consistente con la distinción entre enmienda y revisión que encontramos en ciertas constituciones, donde la última implica un cambio de mayor escala.

La Corte Constitucional de Colombia siguió un camino similar. La constitución permitía a la corte revisar las enmiendas por cuestiones procedimentales, incluyendo un test de competencia de la autoridad que propone las enmiendas. La corte utilizó esta facultad para elaborar una doctrina que distinguía la enmienda del reemplazo, que ninguna autoridad tendría la potestad para efectuar. De este modo, la corte se esta-

${ }^{51}$ El Partido Nacional y el Partido Democrático votaron por la constitución, pero desafiaron la certificación en ciertos puntos. El Partido de la Libertad Inkatha también desafió el documento. Las provisiones incluían aquellas relativas al balance de poder federal y al hecho de que la bill of rights no estaba lo suficientemente resguardada. 
bleció a sí misma como el guardián que habría de asegurar que ninguna enmienda excediera cierto límite indefinido.

En términos más generales, las cortes constitucionales se han vuelto bastante activas en la elaboración de políticas para las enmiendas constitucionales, en algunos casos en términos sustantivos y en otros casos en términos procedimentales. Algunas de estas cortes (comenzando por la de India) han desarrollado la idea de que ciertas enmiendas no pueden realizarse porque importarían un cambio en la estructura fundamental de la constitución: no se trata ya de certificar el documento inicial, sino de cómo una corte podría sostener que una constitución es inconstitucional.

En otros Estados, cuyas constituciones detallan procedimientos para "revisiones totales" y "revisiones parciales", como son los casos de Austria o Nicaragua, las cortes se declaran en ocasiones ellas mismas competentes para definir aquella distinción. Aun sin apoyo textual, algunas cortes han elaborado la distinción. Un ejemplo es Corea del Sur, cuando se resuelve que el gobierno no puede cumplir la promesa de campaña de trasladar la ciudad capital. La corte invocó una "constitución de la costumbre" no escrita, la que no podía ser modificada sin un referéndum. En este caso, la corte estaba ocultando su aumento de poder (inventando un texto no escrito que sólo ésta podía ver) por medio de afirmar que cierto nivel de apoyo popular sería un requisito para el cambio propuesto.

En el ejemplo de Islandia mencionado más arriba, la carta del parlamento que validaba la "constitución ciudadana" redactada en la etapa posterior a la crisis financiera había llamado, entre otras cosas, a la elección de 25 ciudadanos para componer la comisión constitucional. La corte suprema del país, sin embargo, invalidó la elección. El parlamento decidió nombrar a todos los miembros elegidos, de modo que tuvo pocas consecuencias. Otro ejemplo negativo tuvo lugar en Egipto en junio de 2012, cuando la corte constitucional disolvió la asamblea popular. La amenaza de acciones ulteriores por parte de las cortes fue lo que motivó al presidente Morsi a imponer su constitución destinada al fracaso, a fines de noviembre de ese año.

Si todo esto es o no democrático no es de nuestra preocupación inmediata. El punto conceptual es que, estando o no autorizadas, las cortes frecuentemente emergen como fiscalizadores policiales en procesos de reforma constitucional. Y esto significa que son un potencial 
actor que debe ser tomado en cuenta en el diseño de un proceso de reforma constitucional.

Las cortes juegan otro papel en el cambio constitucional, uno que es tan obvio que llega a ser invisible. Las cortes modifican la constitución a través de la interpretación constitucional. De este modo, si un sistema político entiende que ciertos problemas merecen atención, empoderar a las cortes puede ser un mecanismo a considerar, aunque sea impredecible. Por ejemplo, la constitución de México ha sido reformada recientemente a fin de permitir a las cortes considerar las reglas de un tratado del que México es parte - incluyendo tratados de derechos humanos - como superiores al derecho doméstico. Esto supone una expansión dramática de las bases normativas de la constitución. Aunque excede el espectro del presente artículo, se podría pensar, como posibilidad para Chile, una reforma a la jurisdicción del Tribunal Constitucional con el objetivo de incentivarlo a adoptar un rol más agresivo ex post - en vez de ex ante- de revisión constitucional. Muchos países de la región han reformados sus sistemas de amparo para reflejar la tendencia moderna hacia una mayor protección judicial de los derechos. No existe una razón obvia para que Chile sea en esto una excepción.

\section{V.c. Rol del pueblo}

Concluimos con algunos comentarios sobre el rol del pueblo en la reforma constitucional. Como lo muestra la figura $n^{\circ} 5$, ha habido una tendencia importante hacia la inclusión de la ciudadanía en el diseño constitucional. En efecto, algunos han sostenido que el derecho a participar del diseño constitucional tiene estatus de norma de derecho internacional $^{52}$. La participación pública aparece en muchas fases en el proceso de diseño constitucional. El pueblo puede ser consultado en el proceso de formulación de ideas para la reforma constitucional; puede monitorear el proceso de redacción; y puede también jugar un rol en la ratificación del producto final a través de un referéndum público.

Estas intervenciones pueden hacer una diferencia real y servir como constreñimiento inferior importante. Por ejemplo, en ciertos casos observamos un rechazo público a proyectos constitucionales: es el caso del proyecto de Wako, en Kenia, que fue rechazado en un referén-

${ }^{52}$ Hart (2003); Franck \& Thiruvengadam (2010). 


\section{FIGURA N ${ }^{\circ}$ 5: $\quad$ TENDENCIA EN APROBACIÓN CIUDADANA A CONSTITUCIONES}

Universo: Constituciones que especifican un procedimiento de promulgación

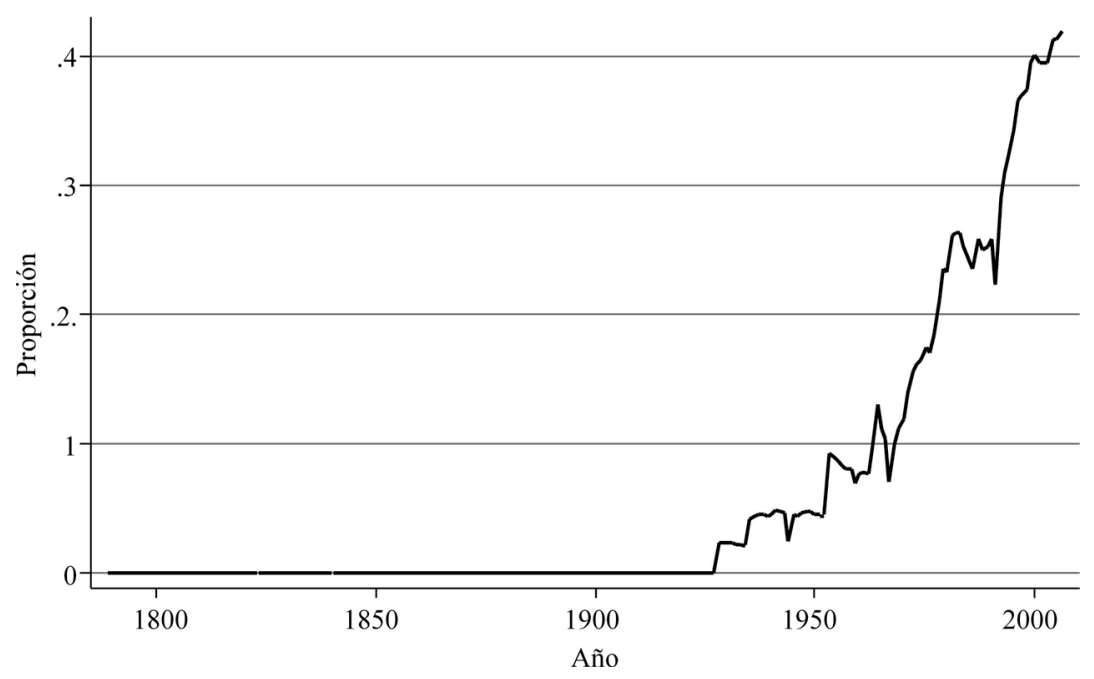

dum en 2005, y en el caso de un proyecto de constitución en las Islas Seychelles que no alcanzó el 60\% de apoyo requerido en 1992. En cada caso, estas expresiones de rechazo dieron origen a intentos renovados de reforma que se tornaron mucho más inclusivos y, en último término, exitosos.

Los ciudadanos en Chile están políticamente informados y en general bien educados. En este sentido, no hay razones de orden teórico para pensar que el pueblo no puede jugar un rol importante en la adopción de una nueva constitución para sí mismo. Es probablemente aconsejable, entonces, que cualquier esfuerzo para reformar la constitución de Chile incluya la voz del pueblo en un estadio final, o muy cerca del final.

\section{Conclusión}

La experiencia chilena es el epítome de lo que aquí hemos caracterizado como constitucionalismo autoritario transformador, en el que la constitución está explícitamente diseñada para retornar a un gobierno civil, pero resguardando ciertos fines políticos más allá de 
la toma democrática de decisiones y estableciendo mecanismos institucionales genuinos para reforzar estos límites. Se trata de una forma genuina de constitucionalismo, incluyendo los elementos esenciales de atrincheramiento y constreñimiento, tanto de gobernantes como de gobernados. Se trata de un arreglo explícitamente temporal, que incluso los fundadores deben reconocer como precario ${ }^{53}$. Pero, convencidos de los méritos de sus preferencias políticas, los fundadores parecen creer que las limitaciones eventualmente serán tan internalizadas por la población como autocontroladoras. En este sentido, se trata de documentos optimistas.

En muchos sentidos, la constitución de Chile de 1980 ha servido a su propósito, como sea que se lo defina. Atrincheró de modo exitoso importantes prioridades de política del régimen militar, al mismo tiempo que facilitó una significativa transición política, y aseguró una fuerte economía de mercado. Aunque considerada muy lenta por los proponentes de la reforma democrática, la transición se ha logrado sin violencia, con la mayoría de las reformas hechas con el apoyo político de los herederos del golpe de 1973.

A la fecha de este trabajo, a fines de 2013, se llama a un cambio, lo que refleja el contexto completamente diferente del Chile actual. Estos llamados son naturales y deben ser tomados en cuenta. Cómo llevarlos a cabo es el gran debate de la política chilena hoy. Mi sugerencia es que la literatura comparada aporta algo de perspectiva sobre la modalidad en virtud de la cual dicha reforma puede ser lograda, ya sea a través de asamblea constituyente o potestad legislativa. Podemos decir, sin embargo, que existen otras posibilidades que deberían ser consideradas. Una conferencia nacional sobre reforma constitucional podría ser un primer paso; el último paso debiera incluir una amplia participación a través de un referéndum constitucional. Y el proceso de redacción entremedio debiera incluir a los partidos políticos existentes, ya que no pueden ser evitados en ningún caso.

${ }^{53}$ Varol (2014). 


\section{BiBLIOGRAFÍA}

Albertus, Michael \& Victor A. Menaldo (2013). "The Political Economy of Autocratic Constitutions.” En Tom Ginsburg \& Alberto Simpser (eds.) (2013). Constitutions in Authoritarian Regimes. New York: Cambridge University Press.

Arato, Andrew (2009). Constitution-Making Under Occupation: The Politics of Imposed Revolution in Iraq. New York: Columbia University Press.

Arato, Julian (2012). "Constitutional Transformation in the ECtHR: Strausbourg's Expansive Recourse to External Rules of International Law." Brooklyn Journal of International Law 37 (Summer). - (2013). "Treaty Interpretation and Constitutional Transformations." Yale Journal of International Law 38 (Summer).

Bali, Asli U. (2012). "The Perils of Judicial Independence: Constitutional Transition and the Turkish Example." Virginia Journal of International Law 52 (Winter).

Barros, Robert (2002). The Constitutionalism and Dictatorship: Pinochet, the Junta, and the 1980 Constitution. Cambridge, United Kingdom: Cambridge University Press.

Canavan, Francis (1987). "The Relevance of the Burke-Paine Controversy to American Political Thought." Review of Politics 69 (Spring).

Elkins, Zachary, Tom Ginsburg \& James Melton (2009). The Endurance of National Constitutions. New York: Cambridge University Press.

- (2013) "The Content of Authoritarian Constitutions." En Tom Ginsburg \& Alberto Simpser (eds.) (2013), Constitutions in Authoritarian Regimes. New York: Cambridge University Press.

Elster, Jon (ed.) (1998). Deliberative Democracy. Cambridge. United Kingdom: Cambridge University Press.

__ (2013). Securities Against Misrule. New York: Cambridge University Press.

Franck, Thomas M. \& Arun K. Thiruvengadam (2010). "Norms of International Law Related to the Constitution-Making Process". En Laurel E. Miller (ed.), Framing the State in Times of Transition: Case Studies in Constitution-Making. Washington DC: United States Institute of Peace.

Ginsburg, Tom (2009). “Constitutional Afterlife." International Journal of Constitutional Law 7 (Winter).

- (April 2013). "Iceland: End of the Constitutional Sage," I-CONnect Blog, disponible en http://www.iconnectblog.com/2013/04/iceland-endof-the-constitutional-saga

Ginsburg, Tom \& Alberto Simpser (eds.) (2013). Constitutions in Authoritarian Regimes. New York: Cambridge University Press.

Ginsburg, Tom, Zachary Elkins \& Justin Blount (2009a). "Citizen as Founder: Public Participation in Constitutional Approval." Temple Law Review 81 (Summer).

- (2009b). "Does the Process of Constitution-Making Matter?" Annual Review of Law \& Society Science 5 (Winter). 
Goldenziel, Jill I. (2013). "Veiled Political Questions: Islamic Dress, Constitutionalism and the Ascendance of Courts." American. Journal of Comparative Law 61 (Winter).

Hart, Vivien (2003). "Democratic Constitution Making” (U.S. Institute of Peace, Special Report No. 107,), disponible en http://ww.usip.org/pubs/ specialreports/sr107.html.

Hilbink, Jill (2007). Judges Beyond Politics in Democracy and Dictatorship: Lessons from Chile. New York: Cambridge University Press.

Horowitz, Donald L. (2013). Constitutional Change and Democracy in Indonesia. New York: Cambridge University Press.

Isiksel, Turkuler (2013). "Between Text \& Context: Turkey's Tradition of Authoritarian Constitutionalism." International Journal of Constitutional Law 11 (Summer).

Jellinek, Georg (1906). "Constitutional Amendment and Constitutional Transformation". En Arthur Jacobson \& Bernhard Schlink (eds.) (2000), Weimar: A Jurisprudence of Crisis. Berkeley: University of California Press.

Kommers, Donald P., John E. Finn \& Gary J. Jacobsohn (2009). American Constitutional Law: Essays, Cases, and Comparative Notes. Maryland: Rowman \& Littlefield Publishers, Inc.

Landau, David (2013). "Constitution-Making Gone Wrong." Alabama Law Review 64 (Winter).

Law, David S. \& Mila Versteeg (2013). "Sham Constitutions.” California Law Review 101 (Summer).

McMahan, Jeff (2002). The Ethics of Killing: Problems at the Margins of Life. New York: Oxford University Press.

Okoth-Okendo, H.W.O. (1993). "Constitutions without Constitutionalism: Reflections on an African Political Paradox". En Douglas Greenberg, Stanley N. Katz \& Melanie Beth Oliviero et al. (eds.), Constitutionalism and Democracy: Transitions in the Contemporary World. New York: Oxford University Press.

Parfit, Derek (1984). Reasons and Persons. New York: Oxford University Press.

Pemstein, Daniel, Stephen Meserve \& James Melton (2010). "Democratic Compromise: A Latent Variable Analysis of Ten Measures of Regime Type." Political Analysis. 18.4: 426-449.

Rosenfeld, Michel (2009). The Identity of the Constitutional Subject: Selfhood, Citizenship, Culture, and Community. New York: Routledge.

Rosenn, Keith S. (1990). "Brazil's New Constitution: An Exercise in Transient Constitutionalism for a Transitional Society." American Journal of Comparative Law 38 (Autumn).

Scheppele, Kim L. (2008). “A Constitution between Past and Future." William \& Mary Law Review 49 (Spring).

Strauss, David A. (2010). The Living Constitution. New York: Oxford University Press.

Teitel, Ruti G. (2000). Transitional Justice. New York: Oxford University Press. (2011). "Transitional Justice and the Transformation of Constitutionalism”. En Rosalind Dixon \& Tom Ginsburg (eds.), The 
Comparative Constitutional Law Handbook. UK: Edward Elgar Publishing.

Tezcur, Gunes M. (2009). "Judicial Activism in Perilous Times: The Turkey Case." Law and Society Review 43 (Spring).

Varol, Ozan O. (2014). "Temporary Constitutions." California Law Review 102.

Widner, Jennifer (2005). "Constitution Writing and Conflict Resolution." Commonwealth Journal of International Affairs 94 (Fall). 